\title{
Changes in the burden of malaria following scale up of malaria control interventions in Mutasa District, Zimbabwe
}

Sungano Mharakurwa ${ }^{1,2}$, Susan L Mutambu ${ }^{3}$, Joseph Mberikunashe ${ }^{4}$, Philip E Thuma ${ }^{1,2}$, William J Moss ${ }^{1}$, Peter R Mason ${ }^{5,6^{*}}$ and for the Southern Africa ICEMR Team

\begin{abstract}
Background: To better understand trends in the burden of malaria and their temporal relationship to control activities, a survey was conducted to assess reported cases of malaria and malaria control activities in Mutasa District, Zimbabwe.
\end{abstract}

Methods: Data on reported malaria cases were abstracted from available records at all three district hospitals, three rural hospitals and 25 rural health clinics in Mutasa District from 2003 to 2011.

Results: Malaria control interventions were scaled up through the support of the Roll Back Malaria Partnership, the Global Fund to Fight AIDS, Tuberculosis and Malaria, and The President's Malaria Initiative. The recommended first-line treatment regimen changed from chloroquine or a combination of chloroquine plus sulphadoxine/ pyrimethamine to artemisinin-based combination therapy, the latter adopted by $70 \%, 95 \%$ and $100 \%$ of health clinics by 2008, 2009 and 2010, respectively. Diagnostic capacity improved, with rapid diagnostic tests (RDTs) available in all health clinics by 2008. Vector control consisted of indoor residual spraying and distribution of longlasting insecticidal nets. The number of reported malaria cases initially increased from levels in 2003 to a peak in 2008 but then declined 39\% from 2008 to 2010. The proportion of suspected cases of malaria in older children and adults remained high, ranging from $75 \%$ to $80 \%$. From 2008 to 2010, the number of RDT positive cases of malaria decreased $35 \%$ but the decrease was greater for children younger than five years of age (60\%) compared to older children and adults (26\%).

Conclusions: The burden of malaria in Mutasa District decreased following the scale up of malaria control interventions. However, the persistent high number of cases in older children and adults highlights the need for strategies to identify locally effective control measures that target all age groups.

Keywords: Malaria, Epidemiology, Transmission, Control, Prevalence, Zimbabwe

\section{Background}

Reductions in the burden of malaria have been reported throughout sub-Saharan Africa following the scale up of interventions under the Roll Back Malaria Partnership, the Global Fund to Fight AIDS, Tuberculosis and Malaria, The President's Malaria Initiative and other public-private partnerships [1]. While these interven-

\footnotetext{
* Correspondence: pmason@brti.co.zw

${ }^{5}$ Biomedical Research and Training Institute, Nicoz Diamond House, Samora

Machel Ave, P.O. Box CY1753, Harare, Zimbabwe

${ }^{6}$ College of Health Sciences University of Zimbabwe, P.O. box A 178,

Avondale Harare, Zimbabwe

Full list of author information is available at the end of the article
}

tions contributed to the decline in malaria burden in many countries, the impact has not been universal, both within and between countries [1,2]. Within southern Africa, wide heterogeneity exists in the burden of malaria following the scale up of malaria control measures. Understanding why there has been sustained malaria reduction in some areas while in others these interventions have not had the same impact is critical to extending locally adapted malaria control efforts, developing new control strategies and achieving malaria elimination in southern Africa.

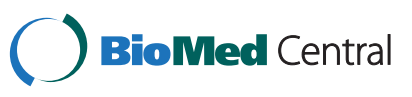


Reductions in malaria incidence in some cases predated the introduction of widespread intervention efforts $[1,3]$, suggesting that other as yet uncharacterized factors are responsible for the reduction in malaria transmission. Multidisciplinary research to ascertain what such factors may be and their relative contribution to the declining burden of malaria is imperative to ensure the effectiveness and sustainability of malaria control and elimination efforts.

The International Centre of Excellence for Malaria Research (ICEMR) in southern Africa aims to better understand the malaria epidemiology, vector biology and parasite genomics in three contrasting epidemiological settings of malaria transmission in Zambia and Zimbabwe [4,5]. A survey was conducted of reported malaria cases and control interventions in Mutasa District, eastern Zimbabwe to better understand trends in the burden of malaria and their temporal relationship to control activities.

\section{Methods}

\section{Study area and population}

Mutasa District has a population of approximately 180,000 persons and is located in a mountainous area of Manicaland Province in eastern Zimbabwe bordering Mozambique. The altitude ranges from less than 600 to more than $1,600 \mathrm{~m}$ above sea level. The low-lying regions of the district, called the Honde Valley, are endemic for malaria and encompass the valleys of the Honde and Pungwe rivers.

Honde Valley consists largely of farmland and several large tea estates. Workers on the estates live in compounds consisting of small housing communities but much of the area consists of small-scale subsistence farms characterized by small villages. In general, the village settlements are concentrated along perennial streams and on hillsides endowed with arable soils. While the streams emanating from the surrounding mountains flow throughout the year, Honde Valley experiences cool (May to July) and hot (August to October) dry periods, with a rainy season extending from November to April. Malaria transmission is seasonal, unstable and epidemic, exacting morbidity and mortality across all ages [6-9]. The vector mosquito species responsible for malaria transmission are not well characterized, although data from the Zimbabwe National Institute of Health Research (NIHR) insecticide resistance surveillance suggest that Anopheles gambiae s. s. is the major malaria vector (Lukwa Nzira 2012, personal communication).

\section{Data collection}

In Mutasa District, health care is delivered through government, missionary and estate health centres, with three district hospitals (Bonda Mission, Hauna and Old Mutare), six rural hospitals and 37 rural health clinics. Data on staffing, vector control interventions, the number of clinical and confirmed cases of malaria and treatment regimens from 2003 to 2011 were collected using a standardized data collection instrument from all three district hospitals and twenty-eight representative health care centers selected by simple random procedure, which included three of the six rural hospitals and 25 of the 37 clinics (Figure 1). Complete data were not available for all clinics as some were established during the study period, and data for 2011 spanned only the first quarter, coinciding with part of the peak malaria transmission season (February to May). Information on coverage with indoor residual insecticide spraying (IRS) and insecticide-treated bed nets (ITNs) was obtained from the NIHR and the National Malaria Control Programme of the Ministry of Health \& Child Welfare that is responsible for implementation of malaria control interventions.

\section{Results}

\section{Health facility staffing}

Only the one district and two mission hospitals had a full-time physician or clinical officer on staff, while the rural hospitals and one estate clinic had physicians who visited weekly. The remaining facilities relied on nursing staff, with state-registered nurses (SRNs) or statecertified nurses $(\mathrm{SCNs})$, primary care nurses $(\mathrm{PCNs})$ and nurse aides (NAs) available to seven, 23 and 30 of the 31 health care facilities, respectively. SRNs undergo threeyear general nurses' professional diploma training, SCNs receive a two-year professional training diploma, and PCNs receive one-year basic training. The district and mission hospitals were the only facilities with laboratory staff capable of performing microscopy. A pharmacy technician was employed only at Bonda Mission Hospital and Hauna Hospital. However, all but seven health care facilities had at least one environmental health technician (EHT) responsible for environmental and disease surveillance.

\section{Vector control activities}

Zimbabwe has had a national malaria control programme comprising vector control with IRS, distribution of ITNs and case management for more than 60 years [10]. Despite economic constraints from 2003 to 2011, vector control continued in Mutasa District. Mutasa District was one of the first districts to be included in the Roll Back Malaria Programme since its launch in Zimbabwe in 2001 and subsequent scale up for impact [10]. Both IRS and ITNs were used for vector control. Although data on coverage with ITNs were not available, the estimated 


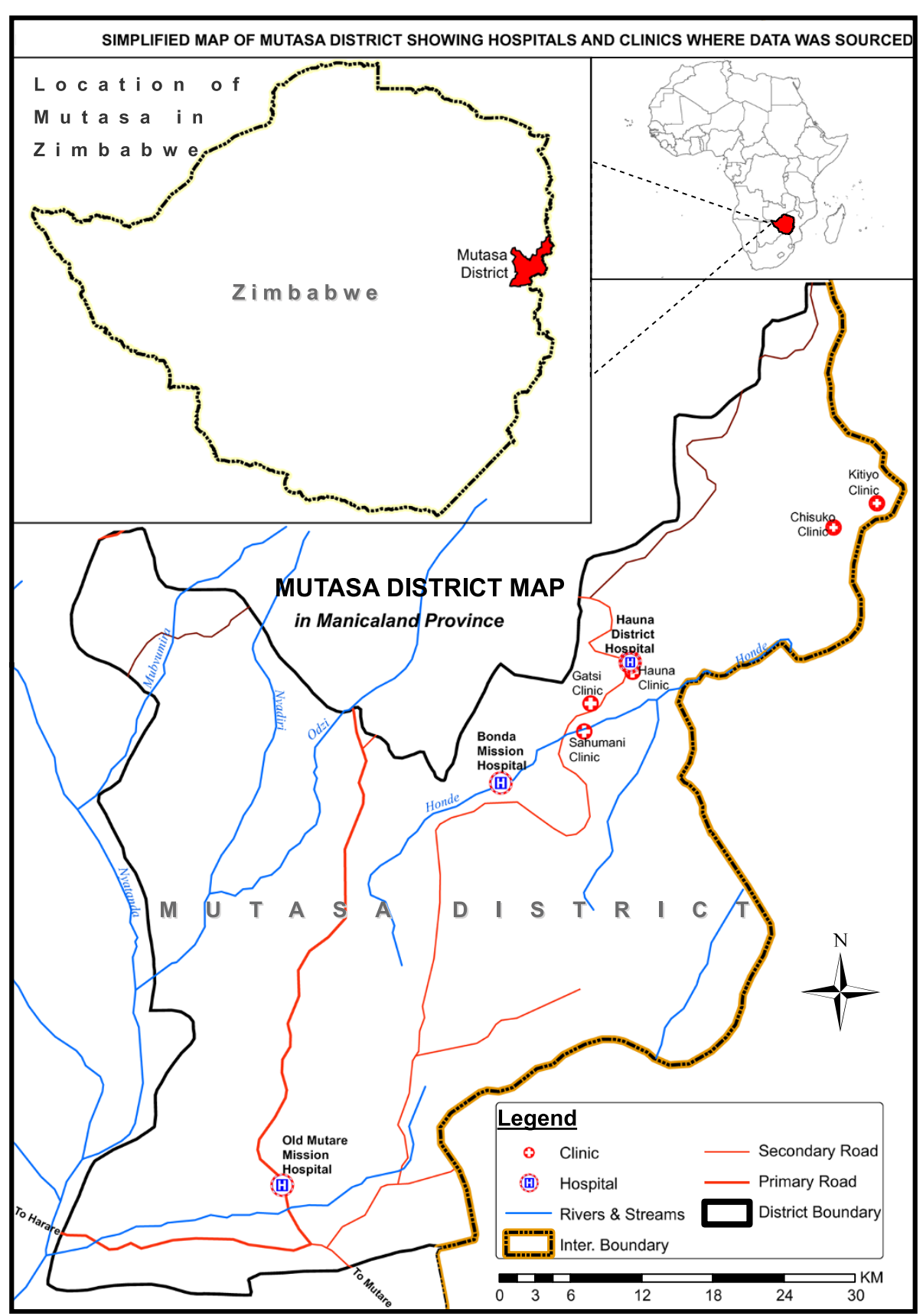

Figure 1 Mutasa District map and location of health care facilities.

proportion of the population protected by IRS in Mutasa District was 92\% and 93\% in 2010 and 2011 [11].

\section{Malaria diagnostics}

Before 2006, most cases of malaria were treated based on clinical criteria, as the availability of microscopy was limited to hospitals. With the introduction of RDTs, access to accurate diagnosis was scaled up, such that all health facilities had access to RDT by 2008. From 2008 to 2011, during which time more than two thirds of suspected cases were tested by RDT, $64 \%$ to $77 \%$ of suspected malaria cases were RDT positive (Table 1).

\section{Malaria treatment regimens}

Anti-malarial treatment regimens changed from chloroquine and chloroquine plus sulphadoxine-pyrimethamine to artemisinin combination therapy (ACT) in 2007 (Figure 2). Chloroquine alone was no longer used after 2008 and ACT was the sole treatment regimen after 2009 (Table 1). 
Table 1 Reported malaria cases, diagnostic tests and treatment regimens by year at health care facilities in Mutasa District, 2003 - 2011

\begin{tabular}{|c|c|c|c|c|c|c|c|c|c|c|}
\hline Year & & 2003 & 2004 & 2005 & 2006 & 2007 & 2008 & 2009 & 2010 & $2011^{*}$ \\
\hline Number of reporting health care facilities & & 24 & 27 & 28 & 29 & 31 & 31 & 31 & 31 & 31 \\
\hline \multirow[t]{3}{*}{ Reported number of suspected malaria cases } & Total & 31,782 & 50,630 & 62,933 & 79,994 & 74,226 & 101,531 & 73,619 & 61,607 & 50,798 \\
\hline & $<5$ years & 7,974 & 12,464 & 13,948 & 15,611 & 15,812 & 22,978 & 14,991 & 12,035 & 12,476 \\
\hline & $\geq 5$ years & 23,808 & 38,166 & 48,985 & 64,383 & 58,414 & 78,553 & 58,628 & 49,572 & 38,322 \\
\hline \multirow{2}{*}{$\begin{array}{l}\text { Proportion of suspected malaria } \\
\text { cases by age category }\end{array}$} & $<5$ years & $25 \%$ & $25 \%$ & $22 \%$ & $20 \%$ & $21 \%$ & $23 \%$ & $20 \%$ & $20 \%$ & $25 \%$ \\
\hline & $\geq 5$ years & $75 \%$ & $75 \%$ & $78 \%$ & $80 \%$ & $79 \%$ & $77 \%$ & $80 \%$ & $80 \%$ & $75 \%$ \\
\hline \multirow[t]{2}{*}{ Reported number of diagnostic tests performed } & Microscopy & 324 & 187 & 796 & 850 & 22 & 9 & 46 & 0 & 0 \\
\hline & RDT & 0 & 0 & 704 & 702 & 11996 & 65868 & 62912 & 50717 & 39207 \\
\hline $\begin{array}{l}\text { Proportion of suspected malaria } \\
\text { cases tested by RTD }\end{array}$ & & $0 \%$ & $0 \%$ & $1 \%$ & $1 \%$ & $16 \%$ & $65 \%$ & $85 \%$ & $82 \%$ & $77 \%$ \\
\hline \multirow[t]{3}{*}{ Reported number of RDT positive malaria cases } & Total & 0 & 0 & 328 & 322 & 6561 & 50462 & 44326 & 32641 & 28098 \\
\hline & $<5$ years & 0 & 0 & 124 & 50 & 1098 & 13788 & 8565 & 5471 & 5631 \\
\hline & $\geq 5$ years & 0 & 0 & 204 & 272 & 5463 & 36674 & 35761 & 27170 & 22467 \\
\hline \multirow{3}{*}{$\begin{array}{l}\text { Proportion of suspected malaria } \\
\text { cases confirmed by RDT }\end{array}$} & Total & $0 \%$ & $0 \%$ & $47 \%$ & $46 \%$ & $55 \%$ & $77 \%$ & $70 \%$ & $64 \%$ & $72 \%$ \\
\hline & $<5$ years & $0 \%$ & $0 \%$ & $41 \%$ & $58 \%$ & $53 \%$ & $78 \%$ & $73 \%$ & $58 \%$ & $57 \%$ \\
\hline & $\geq 5$ years & $0 \%$ & $0 \%$ & $51 \%$ & $44 \%$ & $55 \%$ & $76 \%$ & $70 \%$ & $66 \%$ & $77 \%$ \\
\hline \multirow{4}{*}{$\begin{array}{l}\text { Reported number of treated } \\
\text { cases by drug regimen }\end{array}$} & Total & 31,782 & 51,630 & 62,933 & 79,994 & 74,226 & 101,531 & 73,619 & 61,607 & 50,798 \\
\hline & $\mathrm{CQ}$ & 20,151 & 15,838 & 18,886 & 20,129 & 19,320 & 13,924 & 0 & 0 & 0 \\
\hline & $C Q+S / P$ & 11,631 & 35,792 & 44,047 & 59,865 & 41,764 & 2,955 & 344 & 0 & 0 \\
\hline & $\mathrm{ACT}$ & 0 & 0 & 0 & 0 & 13,142 & 84,652 & 73,275 & 61,607 & 50,798 \\
\hline \multirow[t]{3}{*}{ Reported number of non-malaria cases } & Total & 114,148 & 143,130 & 171,116 & 163,153 & 171,630 & 162,524 & 177,578 & 184,396 & 96,826 \\
\hline & $<5$ years & 24,962 & 30,791 & 36,919 & 29,773 & 28,170 & 46,325 & 58,464 & 65,515 & 34,501 \\
\hline & $\geq 5$ years & 89,186 & 112,339 & 134,197 & 133,380 & 143,460 & 116,199 & 119,114 & 118,881 & 62,325 \\
\hline \multirow{2}{*}{$\begin{array}{l}\text { Proportion of suspected malaria } \\
\text { cases of all clinic cases }\end{array}$} & $<5$ years & $24 \%$ & $29 \%$ & $27 \%$ & $34 \%$ & $36 \%$ & $33 \%$ & $20 \%$ & $16 \%$ & $27 \%$ \\
\hline & $\geq 5$ years & $21 \%$ & $25 \%$ & $27 \%$ & $33 \%$ & $29 \%$ & $40 \%$ & $33 \%$ & $29 \%$ & $38 \%$ \\
\hline
\end{tabular}

* First quarter only.

\section{Changing burden of malaria}

The number of suspected cases of malaria increased from 2003 to a peak in 2008 but then declined 39\% from 2008 to 2010 (Figure 2). The proportion of all suspected cases of malaria in children younger than five years of age ranged from 20 to $25 \%$. Conversely, the proportion of all suspected cases of malaria in older children and adults remained high from 2003 to 2011, ranging from 75 to $80 \%$. From 2008 to 2010, the overall number of RDT positive cases of malaria decreased $35 \%$ but the decline was greater for children younger than five years of age $(60 \%)$ compared to older children and adults (26\%).

\section{Discussion}

This malaria survey in Mutasa District showed a decline in suspected number of malaria cases from a peak in 2008 following increased coverage with malaria control interventions. What was striking was the greater decline in RDT-positive cases among children younger than five years compared to older children and adults. As scale up of diagnostics, effective treatment regimens and vector control was implemented, the asymmetric decrease in malaria among different age groups poses a challenge to control and elimination efforts.

Although the malaria vectors in Mutasa District are not well characterized, malaria transmission increased despite coverage with IRS and ITNs [12,13]. Coverage with vector control interventions as reported by the National Malaria Control Programme, particularly for ITNs, was higher in Mutasa District than that reported for many endemic countries [14], although district level data do not reflect national or provincial coverage levels. The modest impact of these control methods, particularly in older children and adults, may indicate vector species that are biologically or behaviourally resistant to the interventions. Presumably, indoor-based interventions worked better in protecting young children but not persons of older ages who are more likely to be bitten during farming and other occupational activities. 


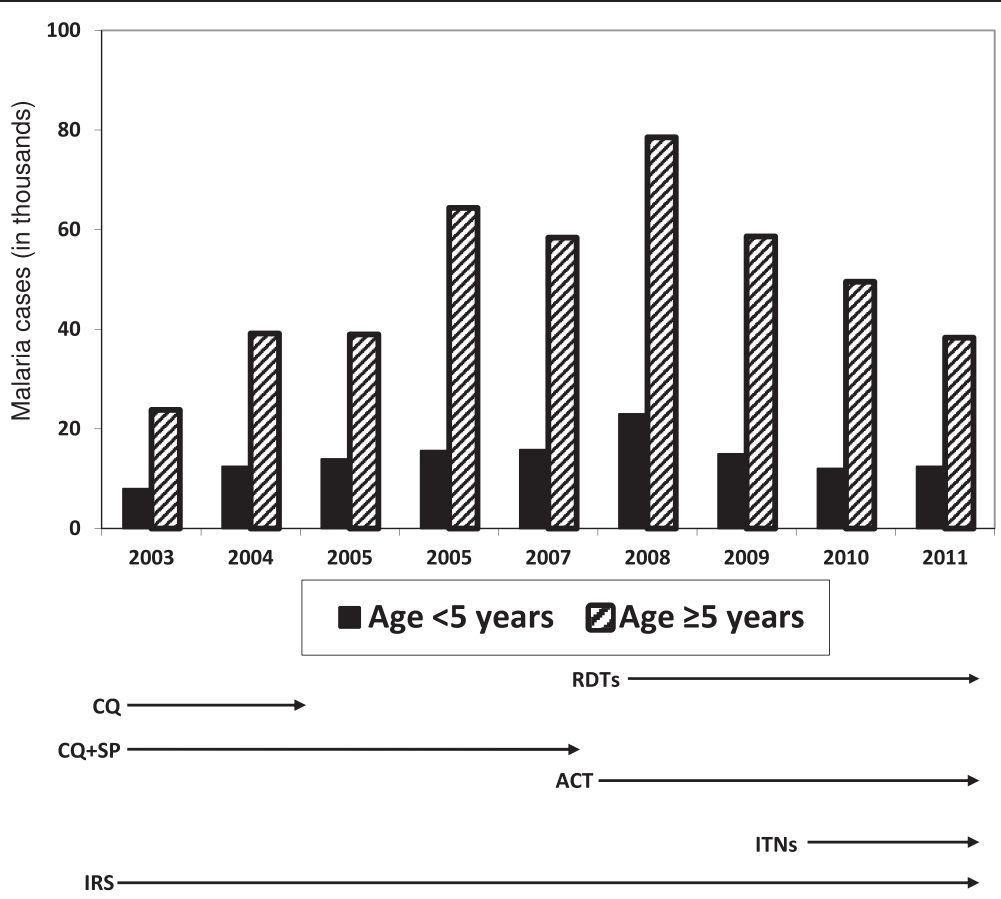

Figure 2 Number of suspected malaria cases by year in persons younger and older than five years of age in Mutasa District.

The malarial burden in Africa remains heterogeneous among areas undergoing apparently similar intervention efforts [3]. In Ethiopia, there was a $>60 \%$ reduction in malaria incidence following the introduction of IRS [15], but resurgent malaria despite extensive availability of ITNs was reported from Kenya [16]. Cryptic outdoorfeeding vectors have been reported recently from western Kenya as a potential cause of sustained transmission in areas with high coverage with IRS or ITNs [17]. Extensive use of ITNs has been reported to alter the composition of the vector complex, with relative reductions in An. gambiae s.s. and Anopheles funestus compared with Anopheles arabiensis [16,18]. Changes in the composition of the vector complex in Tanzania paralleled a dramatic decline in malaria transmission [19]. In areas where An. gambiae has acquired resistance to pyrethroids, ITNs are no more effective than untreated nets in reducing biting [20]. Clearly, understanding the vector biology in Mutasa District is critical to designing effective and sustainable control strategies.

Overdiagnosis of malaria based on clinical suspicion is a known problem in Africa [21] and elsewhere, and confirmatory diagnosis is recommended. RDTs have been shown to be a cost-effective measure to ensure malaria treatment is directed to those who are infected [22,23]. In Mutasa District, the use of RDT increased to approximately $80 \%$ of suspected cases and up to $75 \%$ of RDT were positive. The trend of increasing RDT positivity despite malaria control measures could reflect improved health staff selection of patients likely to have malaria. However, the improvement would have been specific for individuals older than five years. The proportion of all clinic cases that are RDT positive is known to decline when the burden of malaria is reduced, as other conditions become the primary cause for febrile presentations [24].

Modest reductions in the prevalence of malaria were observed following the introduction of ACT in Tanzania [25] and other areas in sub-Saharan Africa. These reductions in malaria prevalence appear to have occurred, in some areas, prior to local scale up of the vector control and the introduction of ACT. Low malaria prevalence hinders the ability to measure the impact of malaria control interventions. For example, an attempt to show the efficacy of gametocidal treatment in reducing malaria transmission in a low transmission region of Tanzania was not possible because of the reduction in malaria transmission in control villages [26].

\section{Conclusions}

The burden of malaria in Mutasa District decreased following the scale up of malaria control interventions. However, the persistent high number of cases in older children and adults highlights the need for strategies to identify locally effective control measures that target all age groups. 


\section{Competing interests}

The authors declare that they have no competing interests.

\section{Authors' contributions}

SM worked on the design of the study, data analysis and write up of the manuscript. MM helped coordinate the field team, collected data and reviewed the manuscript. SLM helped in the design of the study, provided National Institute of Health Research data and reviewed the manuscript. JM was the director of the National Malaria Control Programme, provided health centre data and reviewed the manuscript. PET helped provide clinical expertise and contributed to analysis and write-up of the manuscript. WJM served as part of ICEMR programme directorate and provided guidance as well as review of the manuscript. PRM was the local country PI who initiated the survey, worked on the study design and contributed to data analysis and writing of the manuscript. All authors read and approved the final manuscript.

\section{Acknowledgements}

We are grateful to the district health team of Mutasa District, the Provincial Health Team of Manicaland Province, the National Malaria Control Programme team and the Ministry of Health and Child Welfare, Zimbabwe for access to health centre data. We wish to thank Professor Simon Gregson, Dr Constance Nyamukapa, Edith Mpandaguta and the Manicaland HIV Prevention team for facilitating initial contact with Mutasa District and Manicaland Provincial Health authorities.

This work was supported by the Division of Microbiology and Infectious Diseases, National Institutes of Allergy and Infectious Diseases, National Institutes of Health. For the Southern Africa ICEMR Team: The Southern Africa ICEMR team includes: Peter Agre, Lovemore Gwanzura, Tamaki Kobayashi, Nzira Lukwa, Munashe Madinga, Edmore Mamini, Shungu Munyati, Bhiza J Musana, Douglas E Norris and Clive Shiff.

\section{Author details}

${ }^{1}$ Johns Hopkins Malaria Research Institute, Bloomberg School of Public Health, Johns Hopkins University, 615 North Wolfe Street, Baltimore, MD 21205, USA. ${ }^{2}$ Macha Research Trust, Namwala Road, P.O. Box 630166, Choma, Zambia. ${ }^{3}$ National Institute of Health Research, P.O. Box 573, Harare, Zimbabwe. ${ }^{4}$ National Malaria Control Programme, Ministry of Health and Child Welfare, Harare, Zimbabwe. ${ }^{5}$ Biomedical Research and Training Institute, Nicoz Diamond House, Samora Machel Ave, P.O. Box CY1753, Harare, Zimbabwe. ${ }^{6}$ College of Health Sciences University of Zimbabwe, P.O. box A 178, Avondale Harare, Zimbabwe.

Received: 4 March 2013 Accepted: 24 June 2013

Published: 1 July 2013

\section{References}

1. O'Meara WP, Mangeni JN, Steketee R, Greenwood B: Changes in the burden of malaria in sub-Saharan Africa. Lancet Infect Dis 2010, 10:545-555.

2. DaSilva J, Garanganga B, Teveredzi V, Marx SM, Mason SJ, Connor SJ: Improving epidemic malaria planning, preparedness and response in Southern Africa. Report on the 1st Southern African regional epidemic outlook forum, Harare, Zimbabwe, 26-29 september, 2004. Malar J 2004, 3:37.

3. O'Meara WP, Bejon P, Mwangi TW, Okiro EA, Peshu N, Snow RW, Newton CR, Marsh K: Effect of a fall in malaria transmission on morbidity and mortality in Kilifi, Kenya. Lancet 2008, 372:1555-1562.

4. Mharakurwa S, Thuma PE, Norris DE, Mulenga M, Chalwe V, Chipeta J, Munyati S, Mutambu S, Mason PR: Malaria epidemiology and control in Southern Africa. Acta Trop 2012, 121:202-206.

5. Moss WJ, Norris DE, Mharakurwa S, Scott A, Mulenga M, Mason PR, Chipeta J, Thuma PE: Challenges and prospects for malaria elimination in the Southern Africa region. Acta Trop 2012, 121:207-211.

6. Lukwa N, Nyazema NZ, Curtis CF, Mwaiko GL, Chandiwana SK: People's perceptions about malaria transmission and control using mosquito repellent plants in a locality in Zimbabwe. Cent Afr J Med 1999, 45:64-68.

7. Mharakurwa S, Manyame B, Shiff CJ: Trial of the ParaSight-F test for malaria diagnosis in the primary health care system, Zimbabwe. Trop Med Int Health 1997, 2:544-550.

8. Mharakurwa S, Mutambu SL, Mudyiradima R, Chimbadzwa T, Chandiwana SK, Day KP: Association of house spraying with suppressed levels of drug resistance in Zimbabwe. Malar J 2004, 3:35.
9. Taylor P, Mutambu SL: A review of the malaria situation in Zimbabwe with special reference to the period 1972-1981. Trans R Soc Trop Med Hyg 1986, 80:12-19.

10. Anon: Proposal to strengthen and scale up disease prevention and care for HIV/AIDS, TB and malaria in Zimbabwe, Ministry of Health and Child Welfare Zimbabwe. Harare, Zimbabwe: The Global Fund to Fight AIDS, TB and Malaria proposal; 2002

11. Sande S: Vector control quarter 5 (January to March 2011) report, National Malaria Control Programme MoHaCW. Zimbabwe: Harare; 2011.

12. Bekele D, Belyhun Y, Petros B, Deressa W: Assessment of the effect of insecticide-treated nets and indoor residual spraying for malaria control in three rural kebeles of Adami Tulu District, South Central Ethiopia. Malar J 2012, 11:127.

13. Hamel MJ, Otieno P, Bayoh N, Kariuki S, Were V, Marwanga D, Laserson KF, Williamson J, Slutsker L, Gimnig J: The combination of indoor residual spraying and insecticide-treated nets provides added protection against malaria compared with insecticide-treated nets alone. Am J Trop Med Hyg 2011, 85:1080-1086.

14. Flaxman AD, Fullman N, Otten MW Jr, Menon M, Cibulskis RE, Ng M, Murray CJ, Lim SS: Rapid scaling up of insecticide-treated bed net coverage in Africa and its relationship with development assistance for health: a systematic synthesis of supply, distribution, and household survey data. PLoS Med 2010, 7:e1000328.

15. Hamusse SD, Balcha TT, Belachew T: The impact of indoor residual spraying on malaria incidence in East Shoa Zone, Ethiopia. Glob Health Action 2012, 5:11619.

16. Zhou G, Afrane YA, Vardo-Zalik AM, Atieli H, Zhong D, Wamae P, Himeidan YE, Minakawa N, Githeko AK, Yan G: Changing patterns of malaria epidemiology between 2002 and 2010 in Western Kenya: the fall and rise of malaria. PLoS One 2011, 6:e20318.

17. Stevenson J, St Laurent B, Lobo NF, Cooke MK, Kahindi SC, Oriango RM, Harbach RE, Cox J, Drakeley C: Novel vectors of malaria parasites in the Western highlands of kenya. Emerg Infect Dis 2012, 18:1547-1549.

18. Kitua AY, Mboera L, Magesa SM, Maxwell CA, Curtis CF: The untapped potential of bed nets. Science 2008, 319:900.

19. Derua YA, Alifrangis M, Hosea KM, Meyrowitsch DW, Magesa SM, Pedersen EM, Simonsen PE: Change in composition of the Anopheles gambiae complex and its possible implications for the transmission of malaria and lymphatic filariasis in north-eastern Tanzania. Malar J 2012, 11:188.

20. Asidi A, N'Guessan R, Akogbeto M, Curtis C, Rowland M: Loss of household protection from use of insecticide-treated nets against pyrethroidresistant mosquitoes, benin. Emerg Infect Dis 2012, 18:1101-1106.

21. Doudou MH, Mahamadou A, Ouba I, Lazoumar R, Boubacar B, Arzika I, Zamanka H, Ibrahim ML, Labbo R, Maiguizo S, Girond F, Guillebaud J, Maazou A, Fandeur T: A refined estimate of the malaria burden in Niger. Malar J 2012, 11:89.

22. Batwala V, Magnussen P, Hansen KS, Nuwaha F: Cost-effectiveness of malaria microscopy and rapid diagnostic tests versus presumptive diagnosis: implications for malaria control in Uganda. Malar J 2011, 10:372.

23. Chinkhumba J, Nyanda M, Skarbinski J, Mathanga DP: Performance of two malaria rapid diagnostic tests in febrile adult patients with and without human immunodeficiency virus-1 infection in Blantyre, Malawi. Am J Trop Med Hyg 2012, 86:199-202.

24. Satoguina J, Walther B, Drakeley C, Nwakanma D, Oriero EC, Correa S, Corran P, Conway DJ, Walther M: Comparison of surveillance methods applied to a situation of low malaria prevalence at rural sites in the Gambia and Guinea Bissau. Malar J 2009, 8:274

25. Khatib RA, Skarbinski J, Njau JD, Goodman CA, Elling BF, Kahigwa E, Roberts JM, Macarthur JR, Gutman JR, Kabanywanyi AM, Smith EE, Somi MF, Lyimo T, Mwita A, Genton B, Tanner M, Mills A, Mshinda H, Bloland PB, Abdulla SM, Kachur SP: Routine delivery of artemisinin-based combination treatment at fixed health facilities reduces malaria prevalence in Tanzania: an observational study. Malar J 2012, 11:140.

26. Shekalaghe SA, Drakeley C, van den Bosch S, ter Braak R, van den Bijllaardt W, Mwanziva C, Semvua S, Masokoto A, Mosha F, Teelen K, Hermsen R, Okell L, Gosling R, Sauerwein R, Bousema T: A cluster-randomized trial of mass drug administration with a gametocytocidal drug combination to interrupt malaria transmission in a low endemic area in Tanzania. Malar J 2011, 10:247.

\section{doi:10.1186/1475-2875-12-223}

Cite this article as: Mharakurwa et al:: Changes in the burden of malaria following scale up of malaria control interventions in Mutasa District, Zimbabwe. Malaria Journal 2013 12:223. 